\title{
Migräne ist wohl genetisch bedingt
}

\section{Eine genomweite Linkageanalyse hat weitere neue Loci bei Migräne identifiziert. Eine eindeutige geneti- sche Prädisposition wird immer wahrscheinlicher.}

_ Über die Pathophysiologie der Migräne gibt es immer noch die alte Debatte, ob sie primär eine vaskuläre Dysfunktion oder eine neuronale Dysfunktion mit sekundären vaskulären Veränderungen darstellt. Auf der Suche nach möglichen genetischen Ursachen ist man bei der familiären hemiplegischen Migräne am weitesten gekommen. Für diese autosomal-dominant vererbte Form konnten eindeutige Mutationen identifiziert werden. Bei der „normalen“ Migräne war man sich bislang nicht ganz so sicher, doch konnten schon 13 unabhängige Loci

im Genom mit dem Auftreten von Migräne assoziiert werden.

Für eine Studie wurden nun $59.674 \mathrm{Mi}$ gränepatienten und 316.078 Kontrollen aus 22 Studien zur genomweiten Linkageanalyse zusammengefasst. Dabei wurden 44 unabhängige Einzelnukleotid-Polymorphismen (SNP) entdeckt, die signifikant mit dem Risiko für Migräne assoziiert waren. Hierdurch wurden 38 distinkte Genomloci identifiziert, darunter 28 Loci, über die bis dato noch nicht berichtet worden war. Außerdem wurde der erste Locus auf dem X-Chromosom identifiziert.

In der weiterführenden Analyse der Loci zeigte sich, dass dort vor allem Gene kodiert sind, die in der Gefäßmuskulatur und glatten Muskulatur exprimiert werden.

- Gormley P, Anttila V, Winsvold BS et al. Meta-analysis of 375,000 individuals identifies 38 susceptibility loci for migraine. Nat Genet. 2016;48:856-66

\section{KOMMENTAR}

Es handelt sich um die weltweit bisher größte Studie zur genomweiten Linkageanalyse bei Migräne. Dabei wurden mehrere neue Loci identifizieren - und es zeigte sich auch noch einmal die Assoziation vieler Loci mit Genen, die in Gefäßen exprimiert werden. Zwar sind wir noch lange von einer genetischen Diagnostik der Migräne entfernt, aber die Hinweise auf die genetischen Grundlagen verdichten sich. Einfache Rückschlüsse auf die Pathophysiologie sind vorerst noch nicht erlaubt. Wichtig für die Patienten ist die Botschaft, dass eine eindeutige genetische Prädisposition als Ursache der Migräne immer wahrscheinlicher wird. Sie können die Krankheit als Schicksal betrachten und konsequent behandeln lassen.

Prof. Dr. med. Dr. phil. S. Evers

\section{Hier steht eine Anzeige.}

\author{
블 Springer
}

